\title{
Erratum to: A comparative study of glycoproteomes in androgen- sensitive and -independent prostate cancer cell lines
}

\author{
Anna Drabik • Dorota Ciołczyk-Wierzbicka • \\ Joanna Dulińska-Litewka • Anna Bodzoń-Kułakowska • \\ Piotr Suder · Jerzy Silberring • Piotr Laidler
}

Published online: 4 November 2014

(c) Springer Science+Business Media New York 2014

\section{Erratum to: Mol Cell Biochem (2014) 386:189-198 \\ DOI 10.1007/s11010-013-1857-6}

In the original article, the project number for the funding of part of this study was missing. The Project Number for financing the research which should have been included in the article is K/PBW/000561 - N N401 125638. Everything else in the paper remains correct.

The online version of the original article can be found under doi:10.1007/s11010-013-1857-6.

\footnotetext{
A. Drabik $(\bowtie) \cdot$ A. Bodzoń-Kułakowska $\cdot$ P. Suder .

J. Silberring

Department of Biochemistry and Neurobiology, AGH University

of Science and Technology, Mickiewicza 30 Ave,

30-059 Krakow, Poland

e-mail: drabik@agh.edu.pl

D. Ciołczyk-Wierzbicka $\cdot$ J. Dulińska-Litewka $\cdot$ P. Laidler

Chair of Medical Biochemistry, Jagiellonian University Medical

College, Kopernika 7 Str, 31-034 Krakow, Poland

J. Silberring

Center of Polymer and Carbon Materials, Polish Academy of

Sciences, Sowinskiego 5 Str, 44-121 Gliwice, Poland
} 